\title{
The analysis on causes of failure and strengthening of foundation slab with pre-tensioned CFRP stripes
}

\author{
Tomasz Bartosik ${ }^{1, *}$, Mariusz Szefer ${ }^{2}$, and Lukasz Majchrzyk ${ }^{2}$ \\ ${ }^{1}$ Euro-Projekt, ul. Chopina 32/9, 51-609 Wroclaw, Poland \\ ${ }^{2}$ GSBK Biuro Konstrukcyjne, 192a Królowej Jadwigi street, 30-212 Cracow, Poland
}

\begin{abstract}
The paper presents an example of failure of the foundation slab of a complex of multi-storey buildings and an analysis of the complex reasons of its origin. In addition, the method and technology of the repair was presented in conditions of continuous, though limited operation of the facility, taking into account the existing limitations. The repair involved the necessity of performing specialized preparatory works, proper assembly and protection of the designed strengthening.
\end{abstract}

\section{Description of the structure}

The foundation slab analysed in the paper constitutes the basis for a set of three segments with nine aboveground floors and three underground ones for garages. The whole building was put into operation in 2015. The foundation slab has an area of about $8000 \mathrm{~m}^{2}$ and the shape of an irregular polygon, similar to the deltoid with diagonals of about $160 \times 100 \mathrm{~m}$ (Fig. 1). In the calculation of the foundation slab, the elastic model of foundation was adopted according to the Winkler hypothesis, taking into account the properties of the soil in the region of the foundation. At the stage of implementation of the detailed design, the foundation slab was optimized $-0.70 \mathrm{~m}$ thick slab with local thickenings up to $1.80 \mathrm{~m}$ was designed under the "high" parts, while in the "low" parts $0.40 \mathrm{~m}$ thick slab with thickenings up to $0.70 \mathrm{~m}$ under the columns was calculated. The underground part is dominated by a monolithic column-slab system (columns with dimensions from $0.50 \times 0.50 \mathrm{~m}$ to $0.80 \times 0.80 \mathrm{~m}$, pillars with dimensions up to $0.50 \times 1.75 \mathrm{~m}$ ), complemented along the entire perimeter with external diaphragm walls with a thickness of $0.80 \mathrm{~m}$, and inside the walls of lift and technological shafts with a thickness of 0.20 to $0.40 \mathrm{~m}$. Geological structure was identified up to a maximum depth of $20 \mathrm{~m} \mathrm{bgl}$ at the stage of pre-design geological survey. The foundation was executed about 14 meters below the ground level, on the layer of hard plastic and semi-solid clay.

The underground part was made with the top-down construction method. The diaphragm walls were embedded about 5-6 m below the foundation slab, while the temporary columns were executed using CFA piles and embedded about 5-8 $\mathrm{m}$ below the foundation slab.

\footnotetext{
* Corresponding author: biuro@euro-projekt.net
} 
Floor slabs "-1" and "-2" level are designed with a thickness of $0.25 \mathrm{~m}$ with thickenings up to $0.35 / 0.40 \mathrm{~m}$, while the " 0 " level with a thickness of $0.3 \mathrm{~m}$ with thickenings up to $0.40 / 0.45 \mathrm{~cm}$. The basic, orthogonal grid of supports in the whole object has dimensions of $8.10 \mathrm{~m} \times 8.10 \mathrm{~m}$.

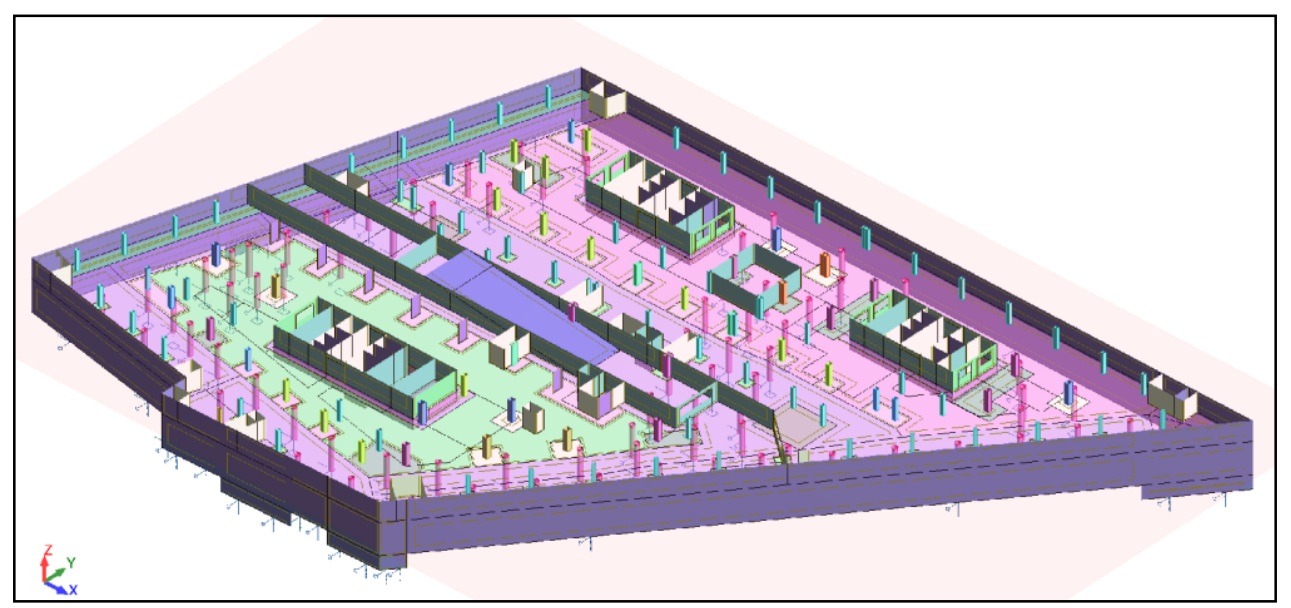

Fig. 1. General view,--3 " storey.

Because the underground part was executed according to the top-down construction method, there were no expansion joint in the level of the foundations and on the slabs of "-2" and "-1" level. Until the foundation slab was finished, subsequent slabs of the underground part were made only around the perimeter of the building as roof slabs. Due to design reasons, an additional slab was planned inside to ensure the required level of stiffening. The roof slabs were supported with temporary steel columns embedded in concrete piles until the whole structure was completed. After construction of the underground part, temporary columns were dismantled from the top to the bottom of foundation. The waterproofing of the foundation slab was designed in Hydrostop technology. The structural discontinuities, i.e. technological and construction joints, expansion joints and punctures were sealed with plastic profiles, bentonite tapes and injection hoses. Under the foundation slab, insulation in the form of a dry mix crystallizing in concrete was applied. Due to ensuring the tightness of the slab, the critical places were connections of cut temporary columns with the foundation slab.

Foundation works were carried out in a dry excavation without the need to lower the ground water table.

\section{Description and scope of the failure and results of the expert evaluation}

\subsection{Description of the failure}

Before the object was put into operation, the appearance of cracks in the upper surface of the foundation, leaks and local water seeping through the foundation slab had been observed. Lack of tightness mainly occurred in the span areas between columns, but also in places of heads of removed temporary columns. During the sealing work, it turned out that in some areas under the foundation slab there is water under considerable pressure. The increase in the extent of damage on the upper surface of the slab along the perimeter of the building parallel to the diaphragm wall was observed (Fig. 2, 3). The local rise of the foundation slab 
was stated after the geodetic survey. Attempts to seal the foundation slab by high pressure injection with materials based on polyurethane and acrylic resins did not bring the expected results.

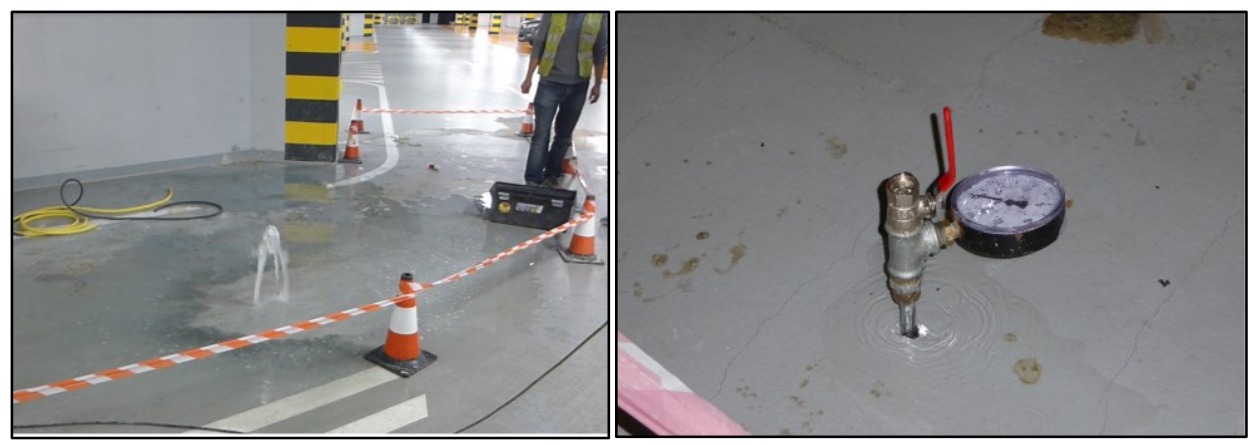

Fig. 2, 3. Drilling through the foundation slab and water pressure measurement.

\subsection{Scope of the tests and technical expertises}

In order to diagnose the problem, an expert program including geotechnical, material and static-strength analysis was carried out, including:

- the expertise describing hydrogeological and geotechnical conditions under the foundation slab, involving:

- execution of additional geotechnical boreholes to the depth of Jurassic layers (depth about $30 \mathrm{~m}$ ) to determine the thickness of Tertiary clay layers, the level of groundwater retention and confirm the source of water supply occurring under the foundation;

- performing physicochemical tests of groundwater in terms of corrosion of concrete;

- drilling through the foundation slab to determine the places of leaks and the amount of water flowing out.

- examination of the foundation slab and expertise of its technical condition including:

- material tests and verification of the compatibility of the placement of the upper layer reinforcement with the design;

- inventory of damage appeared on the foundation;

- static analysis and dimensioning of selected elements of the structure and foundation slab along with checking the correctness of the foundation and reinforcement adopted in the design as well as the method of waterproof insulation;

- determination of the impact of changes in the substrate parameters due to the appearance of water on the correct behaviour of the structure;

- static analysis and dimensioning of selected elements of the structure and foundation slab in the state after the appearance of groundwater under the foundation;

- determination of the causes of damage of the foundation and ways/methods to remedy the situation;

- indication of possible threats and defining the procedure;

- determination of the optimal method of repairing the damage of the foundation slab.

\subsection{Results of the tests, analyses and conclusions}

During geotechnical and hydrogeological survey in one from the boreholes, the occurrence of Upper Jurassic limestone layers was found at a depth of $18 \mathrm{~m} \mathrm{bgl}$. These are fricative and karst aquifers that were not detected during pre-design survey. In this area, the Upper Jurassic 
groundwater level was located at $20.5 \mathrm{~m} \mathrm{bgl}$. As a result of the physico-chemical analysis of the water seeping under the foundation slab, it was found that it is characterized with a very high mineralization, which shows medium chemical aggressiveness in relation to concrete the exposure class XA2.

On the basis of the tests and analyses carried out, the causes of damage of the foundation were determined:

- The building was set on a layer of impermeable clays. The direct foundation was executed in the form of a foundation slab, diaphragm walls and temporary piles. A few meters below them lie weakly permeable layers in the form of clays and mudstones with thin alternating layers of gypsum and fine sands. The coefficient of filtration of clays without interlayers equals $5 \times 10-11 \mathrm{~m} / \mathrm{s}$ and is characteristic for very poorly permeable soils. The permeability in the area of clays increases significantly (practically twice), where the small gypsum lamina $(3-5 \mathrm{~mm})$ increases the filtration coefficient to $3.3 \times 10-7 \mathrm{~m} / \mathrm{s}$.

- Silts in which the excavation, diaphragm wall and temporary piles were executed after being exposed and dried out they undergo up to approx. $0.3 \mathrm{~m}$ depth both horizontal and vertical fractures. These are the expansive ones.

- There are three reasons for the appearance of groundwater under the foundation slab, but it is difficult to determine which contributed directly to the situation. It could have been independently each of them, and it could also be the simultaneous action of all. The reasons are:

- relaxation of the clays under the influence of a deep 13-meter excavation.

- weakening of the layer of impermeable clays due to the execution of a circumferential diaphragm wall with a depth of about 5-6 $\mathrm{m}$ below the foundation slab.

- weakening of the layer of impermeable clays due to the execution of temporary piles supporting temporary columns with a depth of 5-8 m below the foundation slab. The formation of fractures in the layer of impermeable clays and additional stress-relief microfractures and microcracks, as well as weakening in the form of the diaphragm wall and piles caused the transport of water from the aquifer directly to the bottom of foundation. This phenomenon did not happen immediately - hence the lack of water during construction works. It was a rheological process, so that water under high pressure could hollow micro-cracks into the impermeable layers changing them into larger ones and get under the foundation slab.

- Upper Jurassic aquifer level on the eastern side of the buildings is located a few meters higher than from the west. This means that the layer of impermeable clay from the east is more susceptible to leakage due to its smaller thickness.

- Water entering the layer of clays causes their swelling. They are characterized by a very high degree of expansiveness. The swelling ratio is over $50 \%$, and the swelling pressure can be up to about $160 \mathrm{kPa}$.

- The water present under the foundation slab acts by the force of buoyancy with pressure about $30 \mathrm{kPa}$. The area of impact of swelling and buoyancy arising under the slab as well as its range is very difficult or even impossible to estimate.

The influence of water pressure and swelling was not taken into account at the stage of preparing the design documentation, hence numerous damage on the slab in the form of cracks and leaks appeared.

To carry out the analysis for the "emergency" situation, a calculation model of the structure was made, taking into account the influence of groundwater and soil swelling. The value of the swelling pressure was assumed in accordance with the results of the hydrogeological expertise assessment, and its value was set at $p=160 \mathrm{kPa}$. It turned out that the construction of the foundation slab did not have sufficient bearing capacity to transfer impacts from soil swelling and groundwater. 
Additionally, it was found that at the stage of construction works, the designed concrete cover was not preserved locally and the upper reinforcement was placed several tens of millimetres below the designed level, which in the span zone in the areas of $0.40 \mathrm{~m}$ thick slab contributed to a significant reduction of lever arm of the internal forces.

As a possibility of counteracting and repairing the existing situation, it was proposed to use the method of reducing the water pressure under the foundation by installing the drainage system, and then strengthening the top part of slab in the spans, and filling the cracks with injection methods.

\section{Selection of repair and strengthening technology}

The reduction of the water pressure under the foundation was obtained through the use of the original method of draining the zone under the foundation by installing the microwell drainage system.

In the course of analysing the available methods of additional strengthening of the top part in the span area of the $0.40 \mathrm{~m}$ thick foundation slab, the use of steel and composite reinforcement elements was considered. Due to the necessity of placing of the strengthening in the top concrete cover of the slab and the aspect of durability of the strengthening, the use of pre-tensioned CFRP stripes (CFRP - Carbon Fiber Reinforced Polymer) was chosen. Composite systems are a relatively new, dynamically developing technology for the strengthening of building structures. The first world strengthening using stripes with carbon fibres bonded passively to the surface of the reinforced concrete structure were made in 1991 on the bridge Ibach near Lucerne [1]. The first Polish use of composite stripes took place in 1997 when strengthening the bridge over the Wiar river in Przemyśl [2]. These materials are characterized by high strength parameters (significantly exceeding the level achieved by other, commonly available construction materials), speed and ease of application, very good corrosion resistance, low weight and relatively little interference with the existing structure [3]. CFRP materials have linear-elastic characteristics and work without permanent plastic deformation. Moreover, carbon fibres have excellent resistance to dynamic influences and fatigue processes, lack of sensitivity to magnetic fields and almost unlimited length. Due to the manner of impact of the strengthening on the existing structure, two methods are distinguished: passive and active one. Passive strengthening with FRP stripes and mats are an effective way to increase the load-bearing capacity of the structure. Active strengthening is realized using predominantly pre-tensioned carbon fibre stripes. One of the most important aspects accompanying the use of pre-tensioned CFRP stripes is to reduce the deflection of strengthened elements by introducing into the structure a preliminary force reducing existing stresses and deformations. Tensioning the stripe (introduction of pre-deformations) results in much better use of its strength parameters, which is economically justified. In the case of active strengthening of elements, the expected increase in bending resistance is greater than in the case of using passive ones, because in addition to increasing the load capacity of the tensile zone by introducing additional reinforcement (composite), we also increase the load capacity of the concrete compressed zone. The most important positive aspect of the active strengthening of reinforced concrete beams and slabs is the improvement of the serviceability properties of the structure. The reduction of the crack size positively affects the durability and in some cases also the tightness of the structure. Anchorages of the stripes ends are an indispensable element of the active strengthening system in the so-called anchoring systems. During the tension they hold the stripe and allow for the transmission of the prestressing force on the element, while during the use of the strengthened element prevent premature delamination, or provide unproblematic work of the laminate in a situation of partial or total loss of adhesion between the stripe and structure. Active strengthenings with CFRP stripes constitutes so far a very small percentage of all composite strengthenings realized. The first 
such implementation took place in 1998 on the German Lauter bridge in Gomadingen. The first in Poland strengthening of reinforced concrete roof girders by prestressing with carbon fibres stripes was made in 2006 [4], and reinforced concrete slabs in 2010.

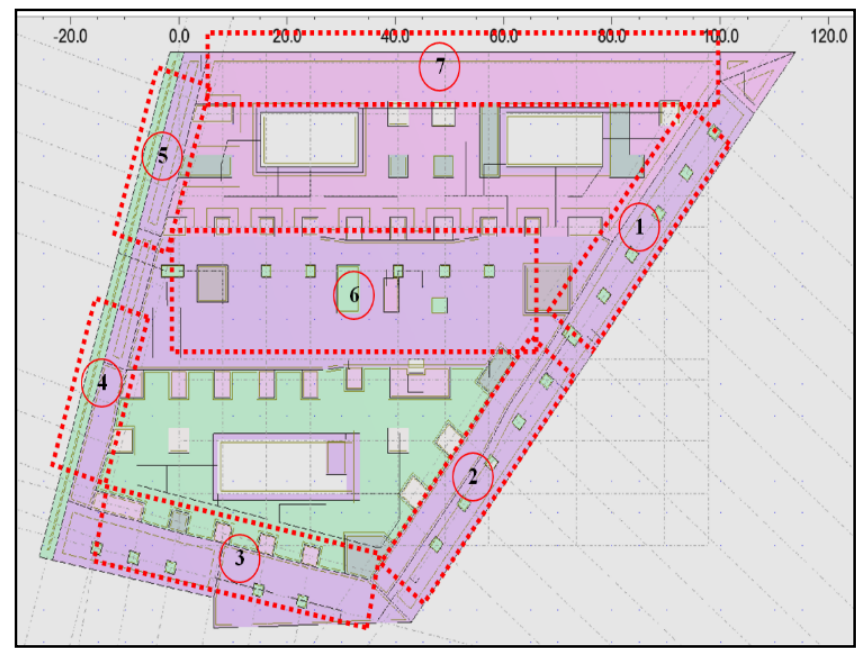

Fig. 4. Foundation slab plan - „-3” storey with 7 zones of strengthening works marked.

To realize the active strengthening of the foundation slab, the S\&P Polska composite system with the original method of prestressing with mechanical anchors was selected, which made it possible to place pre-tensioned stripes at a depth of about $30 \mathrm{~mm}$ below the level of the floor layer.

The slab was divided into 7 zones (Fig. 4). In particular zones there was an insufficient bearing capacity due to SLS or ULS and SLS together. The division into zones and stages was connected with the need for continuous, but limited operation of the garage.

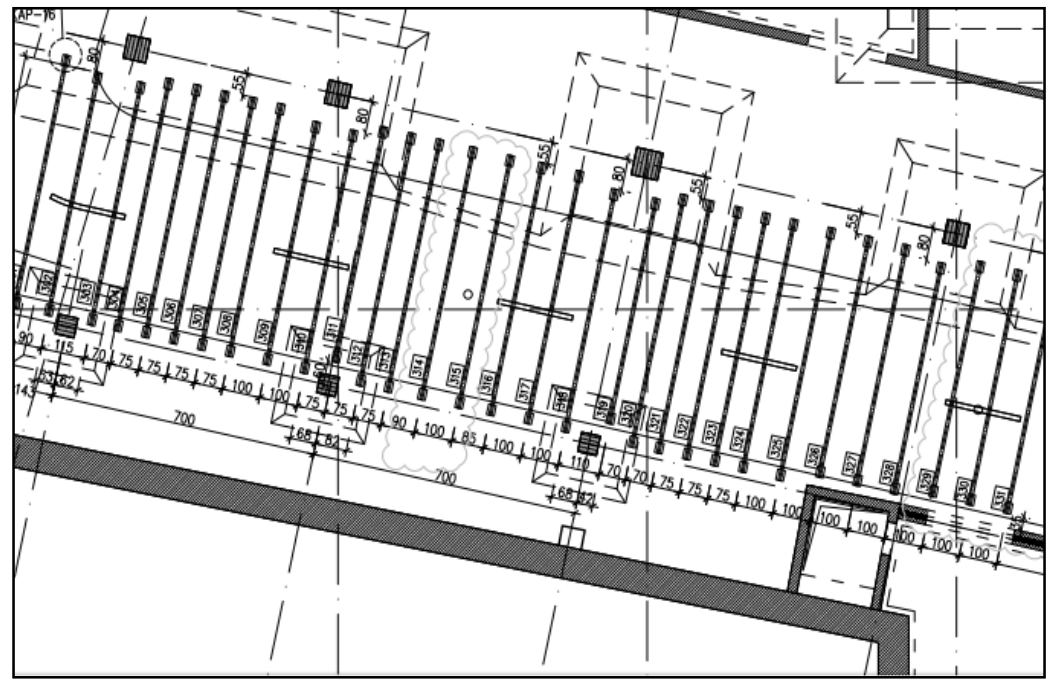

Fig. 5. Fragment of ,-3” storey slab - pre-tensioned stripes layout. 
In order to perform the calculation of strengthenings, the following parameters were assumed, according to the test results:

- $\mathrm{C} 35 / 45$ concrete (increasing the concrete class from C30/37 according to the design) taking into account concrete creep (creep coefficient equals to 3.0),

- top concrete cover - in accordance with the results of ferroscaning,

- bottom concrete cover - designed values of 40/60 mm thick,

- thicknesses of slabs according to the design.

In particular zones, by means of subsequent iterations, the required composite reinforcement was determined to obtain the expected capacity for the strengthened slab and that the crack size does not exceed $0.30 \mathrm{~mm}$. Strengthening stripes with a minimum elastic modulus of $170 \mathrm{GPa}$ and a cross-section of $140 \mathrm{~mm} 2$ (Fig. 5) were assumed to be assembled.

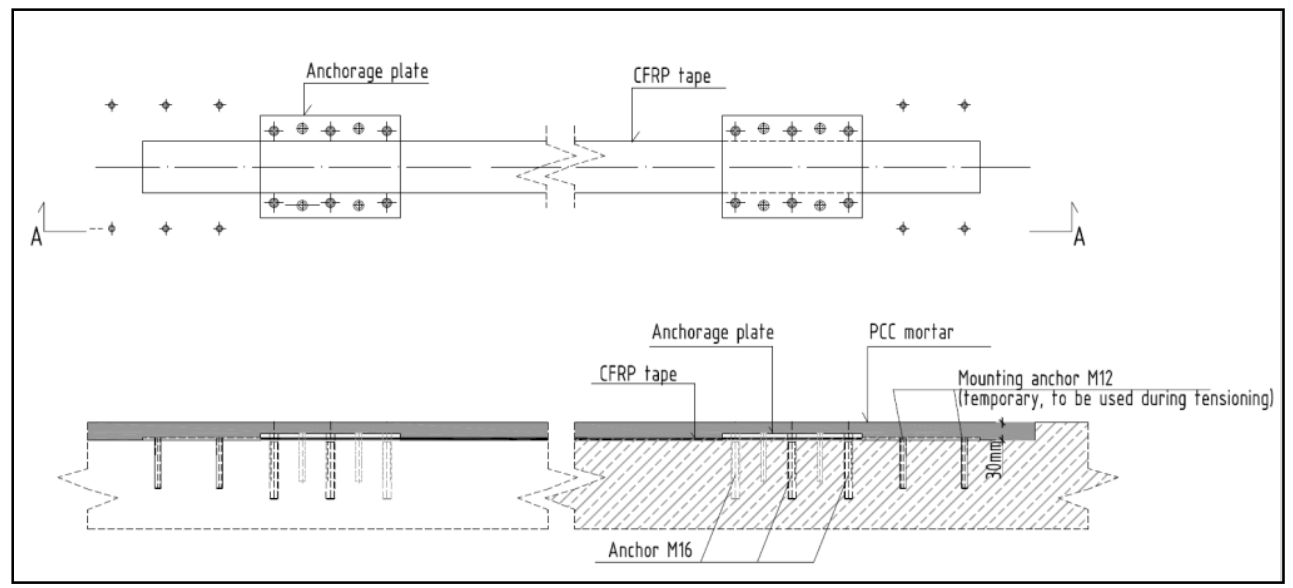

Fig. 6. Scheme of a pre-tensioned stripe with anchorages.

\section{Repair process}

After installing the drainage system and performing the injection to pre-protect the strengthening zone against flooding, prestressing was started. Since the entire facility was operated during the repair, all loud works were carried out at night. The assembly of stripes was planned in the spans of a $0.40 \mathrm{~m}$ thick slab perpendicular to the existing cracks. In order to place the pre-tensioned stripes in the slab's structure, narrow cuts were first made in the top concrete cover to a depth of approximately $30 \mathrm{~mm}$ (Fig. 6). Then the anchoring elements were prepared and the stripes were assembled using prestressing force in the range up to 120 $\mathrm{kN}$. Initial prestressing was achieved by hydraulic jack (Fig. 7, 8), and the level of prestressing was controlled by means of a manometer on the jack and by controlling the deformation of the stripe. The tension control was carried out on the base section between passive and active anchorage. The beginning of the base section at the passive anchorage was the place where the stripe was clamped in the clamping jaws, while the end of the section and the point of strain measurement was the area in the direct vicinity of the active anchorage. Due to the local occurrence of leaks, the epoxy resins binding in a moist environment were used during assembly of the stripes. 

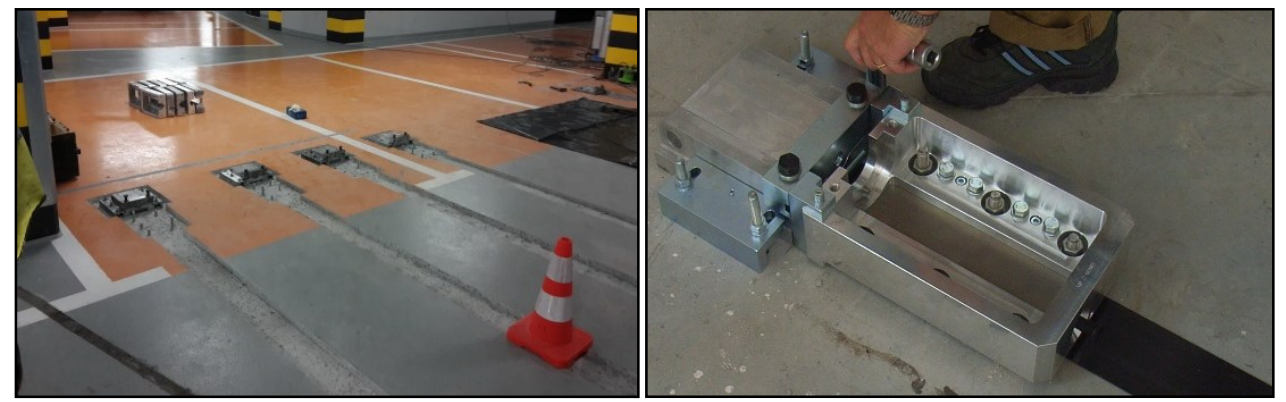

Fig. 7, 8. Assembly of the active and passive anchorage elements.

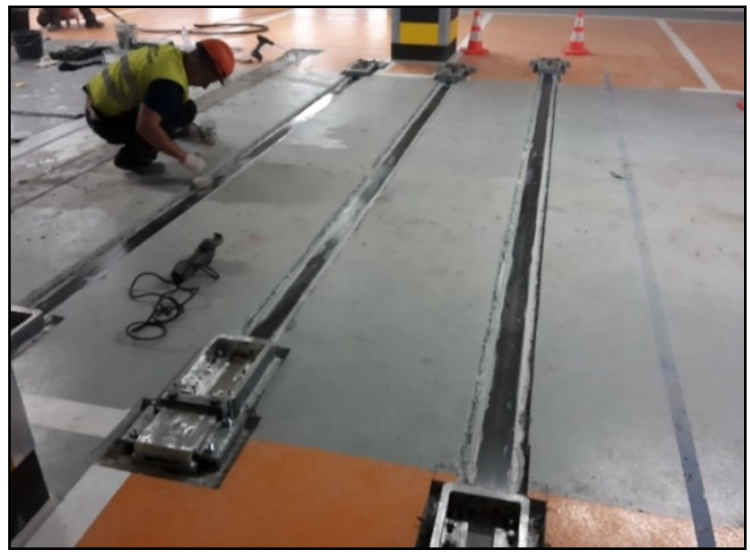

Fig. 9. View of the stripes after prestressing - preparation to reprofilation of finishing layer.

Prestressing of CFRP stripes positively influenced the reduction of crack opening and, as a result, the tightness of the structure. All elements of the reinforcement system were made of stainless steel, so no additional anti-corrosion coatings were used. After assembly and formal acceptance of the stripes, the upper surface of the slab was reprofiled with PCC mortar (Fig. 9, 10). After the prestressing, the last stage of the crack injection was carried out, and finally the resin floor of the garage was recreated. Since the completion of the works described, the building is continuously operated.

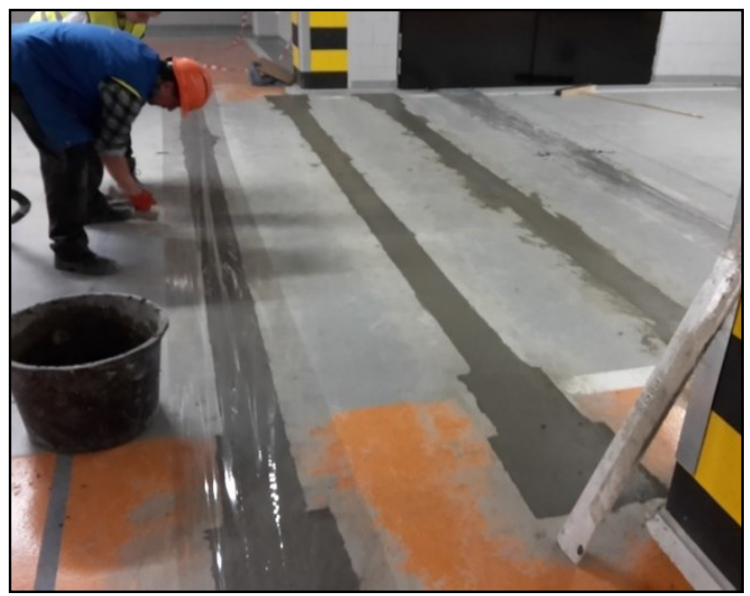

Fig. 10. View of the floor after reprofilation with PCC mortar. 


\section{Summary}

Extensive expert evaluation on the causes of failure of the foundation slab indicates the need for in-depth reflection on the necessary scope of pre-design survey, the adoption of computational assumptions, and the far-reaching optimization of complex spatial structures. The found mistakes in this field caused a serious failure of the building's foundation and forced to bear additional costs of its repair. The paper presents an example of using strengthenings of a reinforced concrete foundation slab with a minimally invasive and economically justified method in the form of pre-tensioned CFRP stripes technology. The prestressing force in composite stripes not only increases the bending capacity, but also reduces existing stresses and strains in the structure. The use of the active method allows for a much more effective, than in the case of passive stripes, the use of very high strength parameters of the composite material, which is economically justified, and the reduction of crack size has a positive effect on the durability and tightness of the structure.

The strengthening method described in the paper realized in 2016 is a successful, first in Poland application of pre-tensioned CFRP stripes to strengthen a damaged foundation slab. The presented technology of active reinforcements, although relatively young, has already emerged definitely from the prototype phase, which is confirmed by several hundred successful global realizations, including several dozen Polish ones. In most cases, such tasks require a very short implementation time due to the fact that most often these are not planned investments. In addition, with currently prevailing standards, users of facilities most often require such construction solutions to be as small as possible from a functional and aesthetic point of view, or to be hidden in structure. The example described in the paper met these expectations. The applied prestressing system is the object of patent protection.

\section{References}

1. Document: U. Meier. SIA/EMFA Documentation D 0128 (Swiss Society of Engineers and Architects, Zurich, Switzerland, 1995)

2. T. Siwowski, W. Radomski. Inżynieria i Budownictwo, 7, pp. 382 - 388 (1998) [in Polish]

3. M. Kałuża, T. Bartosik, (Proceedings of XXIII Conference ,Warsztaty Pracy Projektanta Konstrukcji, t. 1, pp. 1-38, 2006) [in Polish]

4. W. Derkowski. Czasopismo Techniczne. R. 104(9), pp. 265-270 (2007) [in Polish] 